\title{
Liver Neuroendocrine Neoplasm
}

National Cancer Institute

\section{Source}

National Cancer Institute. Liver Neuroendocrine Neoplasm. NCI Thesaurus. Code C96786.

An extremely rare neoplasm with neuroendocrine differentiation that arises from the liver. It includes well differentiated neuroendocrine tumors (carcinoid tumors) and poorly differentiated neuroendocrine carcinomas. 